\title{
Protected areas under pressure: decline, redistribution, local eradication and projected extinction of a threatened predator, the red kite, in Doñana National Park, Spain
}

\author{
Fabrizio Sergio ${ }^{1, *}$, Alessandro Tanferna ${ }^{1}$, Javier Chicano ${ }^{1}$, Julio Blas ${ }^{1}$, \\ Giacomo Tavecchia ${ }^{2}$, Fernando Hiraldo ${ }^{1}$
}

${ }^{1}$ Department of Conservation Biology, Estación Biológica de Doñana - CSIC, C/Americo Vespucio 26, 41092 Seville, Spain

${ }^{2}$ Animal Demography and Ecology Unit, Institute for Mediterranean Studies (IMEDEA), CSIC-UIB, 07190 Esporles, Spain

\begin{abstract}
After a period of overfocus on the establishment of reserves, attention is increasingly being devoted to the capability of protected areas to maintain viable populations of endangered species. Here, we examined the trends and reproduction of the red kite Milvus milvus, a highly endangered raptor near-endemic to Europe, to illustrate the dual benefits and challenges faced by a national park to protect this iconic species. Over the past 4 decades, the kite population of southern Spain has declined steeply and has become progressively confined to Doñana National Park and its buffering Natural Park areas. Population deterioration was also evident within the protected area through (1) spikes of rapid eradication of whole sub-populations from buffer areas, likely propelled by illegal poisoning, and (2) more gradual but steady deterioration of numbers and reproduction, especially in peripheral buffer areas, probably caused by the interplay of several shocks related to food availability, habitat degradation, competition, predation, and chemical contamination. The result was a $46-55 \%$ decline with progressive confinement to the core National Park and an alarming effective population size of $<10$ pairs. Demographic modelling suggested low adult survival and predicted further declines, with possible extinction over the next 2 decades. We outline tentative goals for management, but these will need urgent information on ranging and mortality to provide more efficient targets. These results illustrate how establishment of a large park can prevent regional extinction, but not necessarily guarantee species-safety, leading to protracted forms of extinction debt. We suspect that similar dynamics will become more widespread as anthropogenic pressures increase around protected areas and their performance monitoring becomes more prevalent.
\end{abstract}

KEY WORDS: Matrix models - European estimates - Farmland intensification - Protected area performance $\cdot$ Reserves $\cdot$ Review $\cdot$ Population growth rate

\section{INTRODUCTION}

Protected areas represent one of the pillars of the global conservation strategy (Watson et al. 2014, Beissinger et al. 2017). Despite some recent debate over the breadth of their function (Naughton-Treves et al. 2005), one of the main objectives of protected

${ }^{*}$ Corresponding author: fsergio@ebd.csic.es areas is the protection of biodiversity and the conservation of viable populations of imperiled species (e.g. IUCN 1994). However, mounting pressures within and around protected areas often challenge such goals (Hansen \& DeFries 2007) and, after a period of necessary focus on reserve establishment, more and more attention is being devoted to moni-

() The authors 2019. Open Access under Creative Commons by Attribution Licence. Use, distribution and reproduction are unrestricted. Authors and original publication must be credited. 
toring whether protected areas actually deliver biodiversity benefits, i.e. their performance (Gaston et al. 2008). For example, some studies have reported declines and extinctions of key species in protected areas and sometimes steeper declines within protected areas than outside them (e.g. Brashares et al. 2001, Parks \& Harcourt 2002, Whitfield et al. 2007, Craigie et al. 2010). This calls for the need to assess the historical levels, trends and viability of threatened species within protected areas in order to ensure that they are properly preserved, that they can act as sources of colonizers for outside areas, or that potential declines are detected and halted through management.

Here, we report a representative example of the benefits and challenges provided and faced by protected areas in attaining their biodiversity maintenance function. In particular, we focus on the longterm population dynamics of a highly endangered avian predator, the red kite Milvus milvus, breeding in Doñana National Park in southern Spain.

Doñana is one of the most biodiversity-rich parks in Europe, currently listed as a Ramsar Site, a World Heritage Site, and a UNESCO's Man and the Biosphere Reserve. While it is usually lands of low economic value that are designated as protected areas (e.g. Scott et al. 2001), Doñana is a relatively large park $\left(>1000 \mathrm{~km}^{2}\right)$ centered around a seasonal wetland in prime fertile land along a river estuary. While providing clear biodiversity benefits, its location on very productive land has caused an exponentially growing anthropogenic pressure at the park borders, especially by rapid habitat conversion to intensive farmland, with consequent impacts on the water table that sustains the reserve wetlands. The park is also famous worldwide for its dense populations of charismatic vertebrate predators, which represent a major attraction for over 300000 annual tourists and a key focus for conservation management (e.g. Ferrer \& Hiraldo 1991, López et al. 2009).

One component of such a predator assemblage is the red kite, a medium-sized raptor endemic to the western Palearctic, with $95 \%$ of its world population confined to Europe (Knott et al. 2009). This species, typical of open landscapes with scattered woodland, has suffered dramatic declines in recent decades in all its stronghold populations of Germany, France and Spain, which hold about $80 \%$ of the world population (Knott et al. 2009). Due to such declines, the red kite is currently classed as Near Threatened in the IUCN Red List and included in Annex I of the EU Birds Directive, and in Annex II of the Bern Convention on the Conservation of European Wildlife and
Natural Habitats. In Spain, which holds the world's third largest population, the species has been classified as 'at risk of extinction' since 2011 and as 'at critical risk of extinction' within southern Spain (Andalucía Autonomous Region), where the present study was conducted. In Doñana, the breeding population is concentrated near the marshes (Sergio et al. 2005), where its generalist and opportunist diet is dominated by prey species typical of the marshes and of the ecotone between wetland and terrestrial habitats (e.g. rabbits Oryctolagus cuniculus, waterbirds, carrion and reptiles; Delibes \& García 1984, Veiga \& Hiraldo 1990). The preservation of this population is particularly important for 3 main reasons: (1) It is the last reservoir of the species in southern Spain (see Section 3.1) and thus a strategic key for avoiding further range contraction (a major goal of the European Action Plan for this species; Knott et al. 2009). (2) Its high dependence on a seasonal wetland makes this a unique population (Viñuela et al. 1999, Seoane et al. 2003) with special adaptations to an unpredictable natural disturbance regime of marsh inundation, which would be lost in case of extinction, with the consequent erosion of functional biodiversity. (3) During winter, large numbers of red kite migrants from central-northern Europe join the resident breeding population, which can thus act as a sentinel for mortality threats potentially impacting far away populations through carryover effects.

Given all the above, we reconstruct the historical, regional distribution of the red kite in southern Spain, document its progressive extirpation and confinement to Doñana, demonstrate long-term declines in abundance and performance of the park population across several decades, provide projections of future extinction risk and identify potential threats in urgent need of investigation and management.

\section{METHODS}

\subsection{Study area}

The protected area of Doñana (hereafter Doñana) is located in southwestern Spain $\left(36^{\circ} 56^{\prime} 51^{\prime \prime} \mathrm{N}, 6^{\circ} 21^{\prime}\right.$ 31" E), within the Autonomous Region of Andalucía. It is composed of $542 \mathrm{~km}^{2}$ of National Park, instituted in 1969, and $538 \mathrm{~km}^{2}$ of buffering Natural Park with a less strict protection category, instituted in 1989 (Fig. S1 and Table S1 in the Supplement at www.intres.com/articles/suppl/n038p189_supp.pdf). The National Park is dominated by 5 main habitat types: (1) seasonal marshland, usually flooded during win- 
ter and progressively drying during the springsummer; (2) scrubland, a mixture of different degradation stages of autochthonous Mediterranean scrubland; (3) sparse grassland, mainly located along the interface between Mediterranean scrubland and the marshes (hereafter 'vera'); (4) mobile sand dunes along the ocean shore; and (5) stone pine (Pinus pinea) plantations. Mature trees suitable for nesting kites are mainly present in the latter pinewoods and as isolated or small clumps of cork oaks Quercus suber and Eucalyptus trees. The portions of the Natural Park relevant for breeding kites are mainly the northern and eastern sectors of extensive pinewoods surrounded by intensive farmland. All farmland in and around Doñana has become progressively more intensive, especially with the spread of strawberry cultivation since the 1990s.

\subsection{Field procedures}

Kite territories were censused by looking at territorial displays, nest material transfers and presence of birds perched multiple times in or near their nest during pre-incubation in February-March. Whenever possible, nest contents were checked at least 3 times: (1) during incubation to assess clutch size; (2) just after hatching to estimate hatching success and brood size; and (3) when the nestlings were $\sim 45 \mathrm{~d}$ old to record the number of reared young (nestlings fledge at $\sim 55 d_{i}$ Bustamante 1993). Because kites are extremely vulnerable to poisoned baits (Villafuerte et al. 1998, Viñuela et al. 1999), we collected all available data on kites found poisoned in Doñana. These included (1) individuals reported to local authorities and confirmed as poisoned by subsequent eco-toxicological analysis; and (2) individuals found dead in or under the nest. Based on post-mortem chemical analyses, such cases are extremely likely to be caused by poisoning (details in Hernández et al. 2001).

\subsection{Historical information}

Kites were intensively surveyed until being reasonably sure to have detected the territorial pairs of the whole park since 2012, in collaboration with the park authority and the Equipo de Seguimiento de Procesos Naturales of the Estación Biológica de Doñana-CSIC (EBD-CSIC), which together surveyed the peripheral sectors of Marismillas, Sanlucar pinewood and Abalario (Fig. S1). Before that, intensive research on red kites was conducted in Doñana in the 1980s and 1990s by a group led by F. Hiraldo and subsequently by a group led by F. Sergio and F. Hiraldo (e.g. Veiga \& Hiraldo 1990, Sergio et al. 2005). Work by these research groups focused especially on certain portions of the park and thus integrated extensive information provided by (1) the Equipo de Seguimiento de Procesos Naturales of the EBD-CSIC $_{i}(2)$ the Grupo de Conservación of Doñana National Park; and (3) the field diaries of dozens of researchers, field workers, visitors, volunteers, gamekeepers, park managers and wardens, active in Doñana since the 1960s. Integrating all these sources, especially old field diaries from the 1960s-70s, required $2 \mathrm{yr}$ of careful screening of locational information. For example, two different field observers sometimes visited the same territory in the same year but referred to the site using different local names, which often required meticulous diary inspection to reconstruct the route travelled by each observer on that day. In most years, the census was not available for the whole park and the well surveyed sectors varied among years, depending on research priorities, or the area of action of specific observers (e.g. wardens or field technicians deputed to certain sectors in some years and others in subsequent years). Because of such fragmented surveys, we estimated the total Doñana population by decade as follows: (1) we divided the park into 12 sectors (Fig. 1b). These were defined on the basis of major differences in landscape composition relevant for kite ecology (e.g. extensive pinewoods and farmland in the north of the park, vs. marsh ecotone in the park center) and delineations of private properties, because these often caused abrupt management-driven differences in landscape and because field workers were often assigned to survey whole properties in different years. (2) For each well surveyed sector, we calculated the mean number of pairs per year for each decade. (3) For each decade, we summed up these mean values to obtain a cumulative estimate for that decade. (4) In the few cases in which the first complete survey of a sector was carried out late (e.g. in the 1990s), we assumed that the population was stable in earlier decades (hereafter 'static backestimates'). This was done in order to enable a complete estimate of the whole population through all decades and produced conservative estimates of declines. (5) In the few cases when complete surveys of a sector were not available for a given decade, but they were for earlier and later decades, these were interpolated to estimate the missing value (hereafter 'interpolated estimates'). Finally, (6) in a few peripheral sectors, complete surveys were available for cer- 

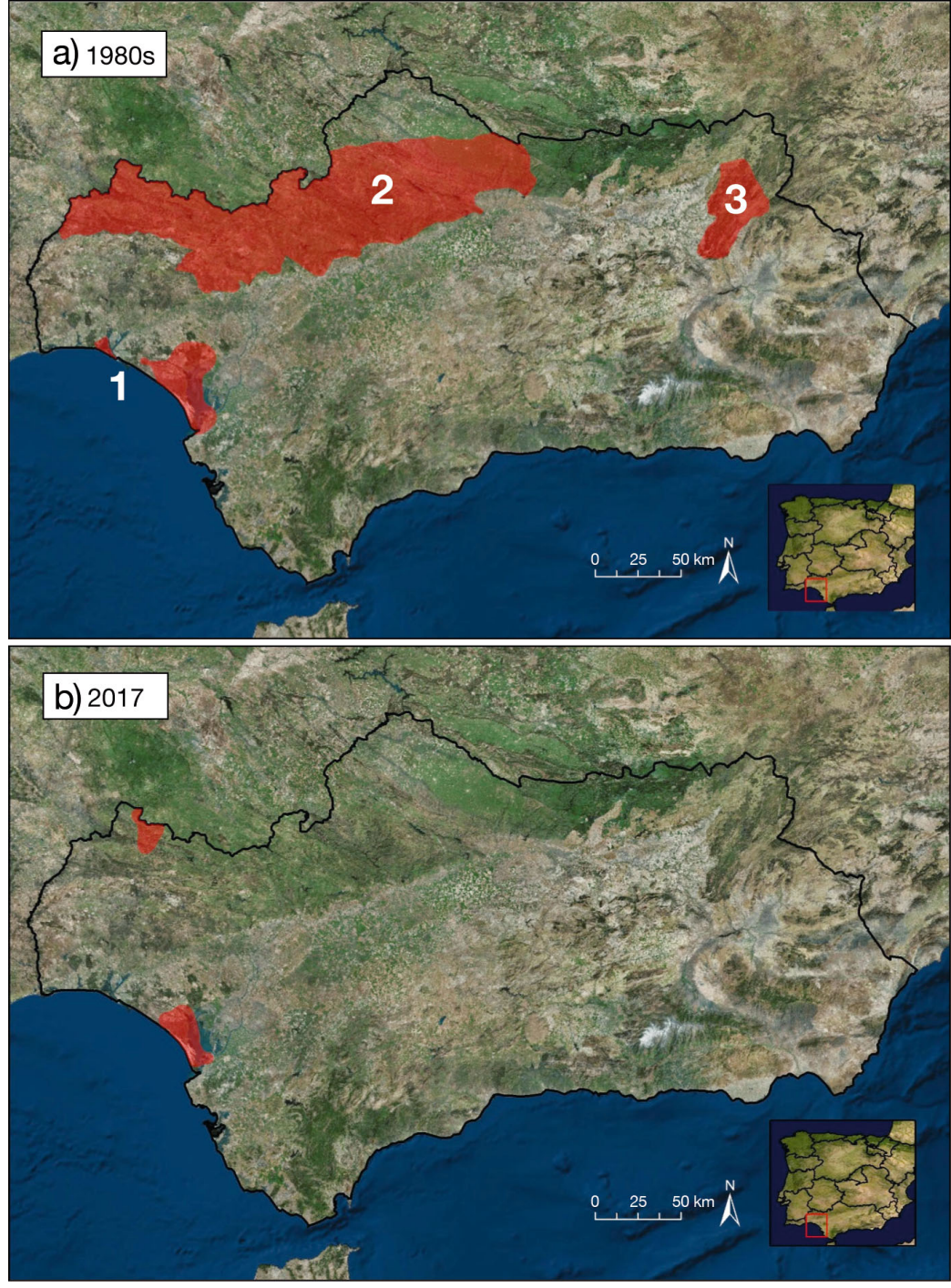

Fig. 1. Approximate distribution range of the red kite in southern Spain (Andalucía Autonomous Region) (a) in the 1980s (reconstructed on the basis of sources cited in Section 2.3) compared to (b) the distribution as recorded in 2017. The red sectors in (a) represent: (1) the marshes of Doñana and Odiel in the provinces of Huelva and Sevilla; (2) the hills and low mountains of Sierra Morena in the provinces of Huelva, Sevilla and Cordoba; and (3) the mountain complex of Cazorla in the provinces of Granada and Jaén

tain portions of a sector in some years and other portions in different subsequent years. In these cases we calculated the mean number of pairs $\mathrm{yr}^{-1}$ decade $^{-1}$ for each subsector when well surveyed, and summed up these means to obtain a cumulative estimate decade $^{-1}$ for the whole sector (hereafter 'cross-combined estimates'). In all procedures above, we ensured that all alternative nests belonging to the same territory were included within the same sector or subsector, in order to avoid biases caused by re-counting the same territory twice when combining different survey units. Similarly, in all cases of doubt, we used the estimate that minimized the historical population, in order to provide conservative estimates of decline.

To place declines and the potential strategic importance of the park within a wider, regional context, we reconstructed the distribution and population levels of the kite population for southern Spain (Andalucía Autonomous Region: $87268 \mathrm{~km}^{2}$ ) in the 1970s-1980s, based on information found in Otero et al. (1978), Torres Esquivias et al. (1981), Ceballos \& Guimerá (1992), Viñuela et al. (1999), Viñuela (2004), and conversations with local experts. Data for the current red kite population outside Doñana were provided by the Consejería de Medio Ambiente of the Andalucía Autonomous Region.

\subsection{Statistical analyses}

To investigate how generalized the historical population declines across different sectors of the park were, we estimated whether the subpopulation of each sector increased or declined between the earliest available survey and the 2010s, and then tested whether declines were prevalent over stable or increasing trends by means of a binomial test. To explore temporal trends in breeding rates, we fitted generalized linear models (GLMs) with decade, sector and their interaction as explanatory variables, and with the likelihood of laying eggs, clutch size, hatching success, brood reduction, the likelihood of successfully raising chicks to fledgling, and the number of young fledged per territorial, breeding and successful pair as response variables (Zuur et al. 2009). In the above analyses, hatching success was defined as the proportion of eggs that hatched, brood reduction was the proportion of hatched chicks lost before fledging, a territorial pair was one that held a territory, a breeding pair one that laid at least 1 egg, and a successful pair one that raised at least 1 nestling to fledging age (>45 d). In particular, the likelihood of laying eggs and raising chicks to fledging were examined through GLMs with binomial errors and a logit link 
function, while clutch size and the number of fledged young were modelled through GLMs with Poisson errors and a log link function. Finally, hatching success and brood reduction were modelled by GLMs with Poisson errors and a log link function, using the number of hatched eggs and the number of disappeared chicks as response variables, and clutch size and brood size at hatching as offset variables (Zuur et al. 2009).

The current expected growth of the Doñana population was estimated by building an age-structured demographic model (Caswell 2001), $M$, based on the age-dependent values of survival (see below) and the mean fertility recorded over the last 5 yr in Doñana (0.294 young per territorial pair). The matrix $M$ describes the transition of the population between 2 consecutive years, $t$ and $t+1$. The asymptotic population growth, $\lambda$, is calculated as the dominant eigenvalue of $M$ (Caswell 2001). In a stable population, $\lambda$ is equal to 1 , while lower values indicate a declining trend. Because survival estimates were not available for the Doñana population, we applied values published for other European populations (reviewed in Table 1). In all studies, survival has been reported for 3 age classes: $1 \mathrm{yr}, 2 \mathrm{yr}$, and adult ( $\geq 3 \mathrm{yr}$ ), so we maintained the same age classes in the current assessment. In particular, to explore the whole range of survival scenarios potentially experienced by our population, we built 3 separate deterministic matrix models, based on the minimum, average and maximum survival rates reported for other European populations, respectively (Table 1 ). These exploratory analyses were conducted with deterministic models because uncertainty on parameter estimates depended largely on the population considered. We further assumed a 1:1 sex ratio and that all kites had entered the breeding population by $3 \mathrm{yr}$ of age.

Table 1. Published estimates of red kite survival by age class. Minimum, mean and maximum levels were used to set up different demographic scenarios for matrix population models

\begin{tabular}{|lllll|}
\hline \multirow{2}{*}{ Area } & \multicolumn{3}{l}{ Age class } & Reference \\
& $1 \mathrm{yr}$ & $2 \mathrm{yr} \geq 3 \mathrm{yr}$ & \\
\hline England, Midlands & 0.80 & 0.94 & 0.93 & Evans et al. (1999) \\
Scotland & 0.37 & 0.72 & 0.87 & Smart et al. (2010) \\
Wales, uplands & 0.60 & 0.79 & 0.94 & Newton et al. (1989) \\
Switzerland & 0.45 & 0.74 & 0.84 & Schaub (2012) \\
Spain, Mallorca & 0.72 & 0.82 & 0.79 & Tavecchia et al. (2012) \\
Spain, Menorca & 0.54 & 0.83 & 0.84 & Sanz Aguilar et al. (2015) \\
Min. European estimates & 0.37 & 0.72 & 0.79 & \\
Mean European estimates & 0.58 & 0.81 & 0.87 & \\
Max. European estimates & 0.80 & 0.94 & 0.94 & \\
\hline
\end{tabular}

Based on the obtained $\lambda$, we then projected the population over the next $10-20 \mathrm{yr}$, assuming no density dependence, to explore its potential short-term viability or extinction over the coming decades. Because of the assumptions outlined above and the parameters taken from other populations, these projections should be taken with caution and recalibrated as more local data become available.

Finally, we used perturbation analyses to calculate the sensitivity, $S(\theta)$, and elasticity, $E(\theta)$, of the population growth rate to a given parameter $\theta$ (Caswell 2001). Sensitivity is the change in population growth rate in response to an absolute change of a given parameter $\theta$, while elasticity is the change in the population growth rate in response to a proportional change of a given parameter $\theta$. Throughout, all analyses were implemented with R version 3.5.1 (R Development Core Team 2018), using the libraries 'popbio' and 'Ime4'. Results are given as means $\pm 1 \mathrm{SE}$, tests are 2 tailed, and statistical significance was set at $\alpha \leq$ 0.05 .

\section{RESULTS}

\subsection{Regional distribution and the strategic importance of the protected area}

Red kites must originally have been common below 400-600 m of elevation throughout Andalucía, which traditionally hosted a dense and well distributed rabbit population as an important prey base (López 1861). By the 1970s-1980s, legal and then illegal shooting and poisoning had reduced the population to 3 main nuclei (Fig. 1a): (1) the marshes of Doñana and Odiel in the provinces of Huelva and Sevilla; (2) the hills and low mountains of Sierra Morena in the provinces of Huelva, Sevilla and Cordoba; and (3) the mountain complex of Cazorla in the provinces of Granada and Jaén. The latter 2 nuclei were reported as 'in steep decline' or documented as already extinct in the 1990s (Viñuela et al. 1999, Viñuela 2004), so that the current regional population is virtually confined to Doñana, with 3 additional relict pairs located in the Sierra de Huelva (Fig. 1b). The nuclei outside the protected area of Doñana were estimated to have suffered a $95 \%$ decline since 
the 1970s-1980s (from a conservative estimate of 40-77 pairs to 2-4 current pairs). Thus, Doñana hosted $52-63 \%$ of the regional population in the 1970s-80s and 95-96\% after 2010, increasing its relative strategic importance.

\subsection{Abundance and trends in Doñana}

Different sectors of the park showed different trends (Fig. 2, Fig. S2). Numbers appeared (1) stable or in moderate decline in the Reserva Biologica de Doñana RBD (sectors 1, 2 and 3); (2) stable or increasing in the sector of Puntal, and in the vera of AlgaidaManecorro as well as its interior. These areas were characterized by the removal of Eucalyptus plantations that converted large areas of woodland to open grassland in the 1990s (sectors 4 and 5), or always maintained a very open landscape through extensive grazing by livestock (sector 6). Finally (3), declines of varying magnitude were observed in all peripheral sectors to the north, east and south. While declines were moderate in the eastern and southern sectors that were monitored less continuously, dramatic declines were evident for all the northern sectors, including portions of the National Park and its buffering Natural Park. In these sectors $(7,8,9)$, a population of 20-25 pairs was basically eradicated in a few years between the late 1980s and early 1990s, remaining virtually extinct to date (Fig. 3). This rapid eradication was accompanied by the detection of adults found dead by poisoning in or under their nest. Overall, there was a significant preponderance of declines between the numbers recorded in the earliest survey available for each sector and the 2010s (binomial test; $\mathrm{p}<0.001$; Fig. 2). Correspondingly, the surface of the overall and core distribution range of the Doñana population declined by 53 and $58 \%$, respectively (Fig. 4).

When summing up all sectors, the overall Doñana population was conservatively (see Section 2.3) estimated at 69 pairs (max. peak of 82) in the 1980s, 61 (max. 86) in the 1990s, 53 (max. 64) in 2000-2009, and 47 (max. 70) in 2010-2017 (Table 2). In 2017, the population was composed of 37 pairs, representing a 46-55\% decline compared to the mean-maximum levels of the $1980 \mathrm{~s}$, i.e. in less than $40 \mathrm{yr}$. Thus, the $\sim 50 \%$ declining rate within the park was high, but was only almost half of the $\sim 95 \%$ decline estimated for outside pairs over the same 4 decades $\chi^{2}=18.4$, $\mathrm{p}<0.0001)$

\subsection{Distribution in Doñana}

Local eradication and differential declines produced a contraction of the overall range and a shift in the relative importance of some sectors. Thus, in the 1980s, the population was well distributed through all sectors, but more concentrated in the core sectors of RBD vera, Puntal and in the northern pinewoods of the Natural Park buffer (Fig. 5a, Table 2). From the 1990s onwards, the population became progressively more concentrated within the National Park, in particular in the ecotonal zone between the marsh and terrestrial habitats, with very low numbers or local extinctions in all the other sectors (Fig. 5b, Table 2).

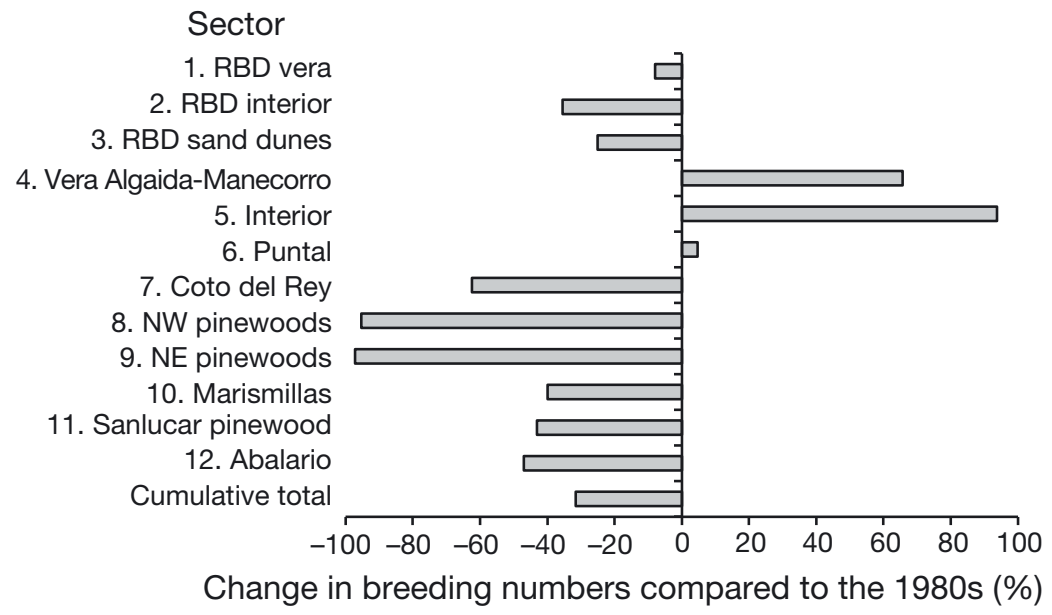

Fig. 2. Percentage change in breeding numbers of the Doñana red kite population by sector from the 1980s, or since the earliest available record (1990s for Puntal and Abalario), to 2017. RBD: Reserva Biologica de Doñana

\subsection{Offspring production in Doñana}

Except for the number of young per successful pair, all breeding parameters deteriorated through time (all $\chi^{2} \geq$ 17.33, all $\mathrm{p}<0.0017)$. The probability of laying eggs, clutch size, hatching success, the likelihood of successfully raising chicks to fledging and the number of young per territorial, breeding and successful pair declined through the last 5 decades, while the extent of brood reduction progressively increased (Fig. 6). Deterioration of reproduction was particularly pronounced for the probability of laying, for brood reduction, for the probability 

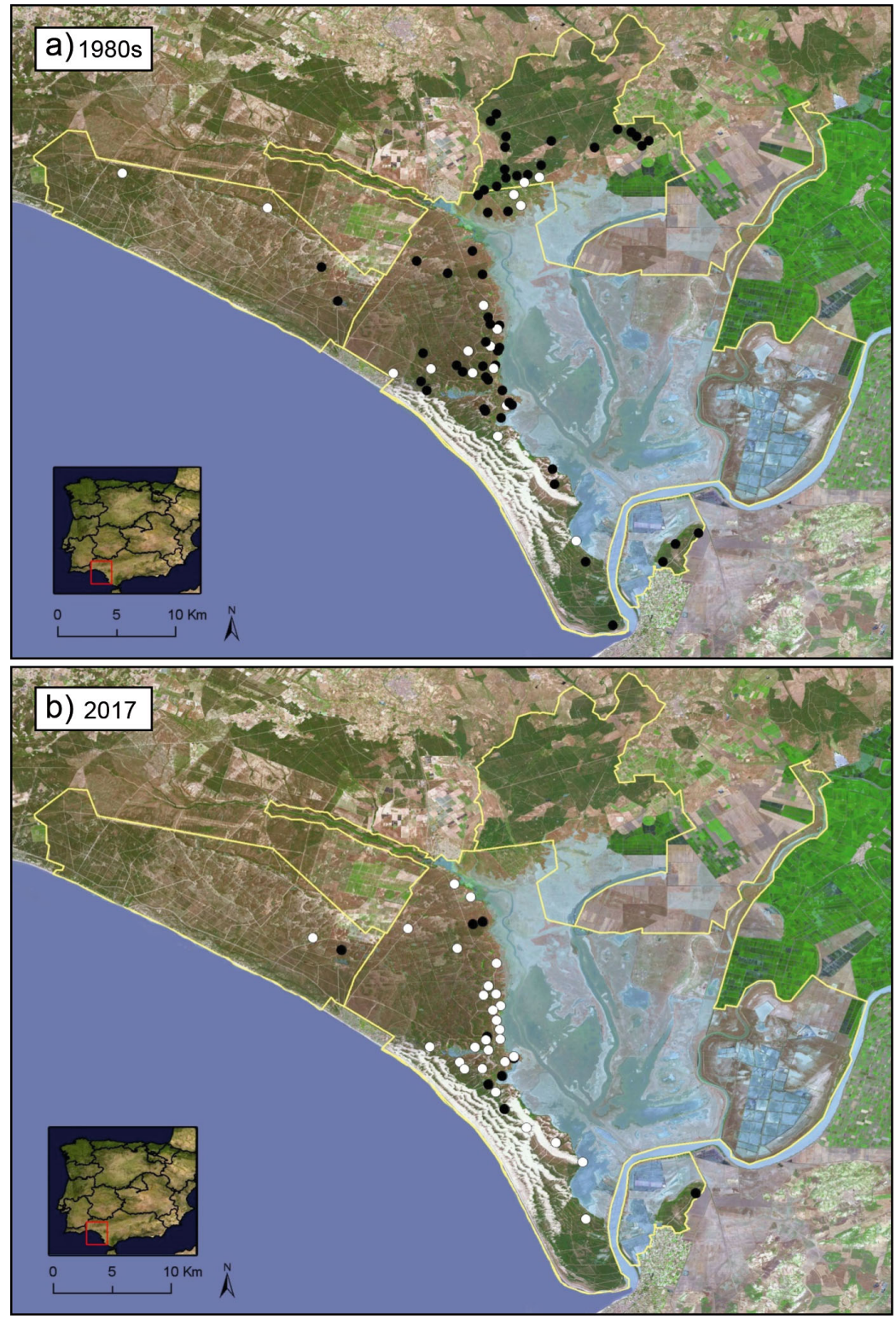

Fig. 3. Distribution of breeding territories in Doñana (a) in the 1980s and (b) in 2017. Pairs that bred successfully (black points) were much more frequent and more widely distributed, especially in the northern sectors and in the Natural Park, in the 1980s than in 2017, when most pairs failed to raise chicks to fledging (white points). Territory locations have been moved slightly for conservation reasons, and locations from the 1980s could only be approximate for some territories, especially those in the northern pinewoods breeding deterioration were accompanied by a change in the relative importance of some sectors for offspring production (Fig. 5, Table 2). In the 1980s, most young were produced in the sector RBD vera and the northern pinewoods, and most other sectors still contributed $>5 \%$ of the annual young production (Fig. 5c). In subsequent decades, fledgling production became concentrated in the marsh ecotone (Puntal, RBD vera, vera of AlgaidaManecorro), with additional inputs from some interior or peripheral sectors, and a larger portion of sectors with virtually zero contribution to future generations (Fig. 5d). Fig. 3 illustrates how diffuse successful reproduction was in the 1980s compared to 2017.

\subsection{Comparison with other European populations}

Compared to other areas of Europe, the Doñana population showed a high density in the 1980s (well above the European mean, Table S3). This progressively declined and has changed to below-average density since 2010 . All breeding parameters were well below the mean European estimates from the 1980s onwards (Table S3). In particular, the percentage of successful pairs and the number of young fledged per breeding pair are currently 2 to 3 times lower than the mean European values.

\subsection{Population growth and projections for the Doñana population}

Observed declines were well capof successful breeding, and for the number of fledged young (Fig. 7).

On average the whole population was estimated to produce 103 fledglings per year in the 1980s; this almost halved to 57 in the 1990s, 48 in 2000-2009 and again declined to more than halved to 19 in 2010-2017. In 2015, 2016 and 2017 the population produced 7, 7 and 15 fledglings, respectively. Population decline and tured by the growth rate predicted by the population model based on the minimum European survival rates (Fig. 8). The other 2 scenarios of maximum and mean survival rates predicted a stable population, or declines from the year 2000 onwards only (Fig. 8). For the 2010s, the model estimated $\lambda=0.849,0.960$ and 1.066 for the scenario based on minimum, mean and maximum survival estimates, respectively. 

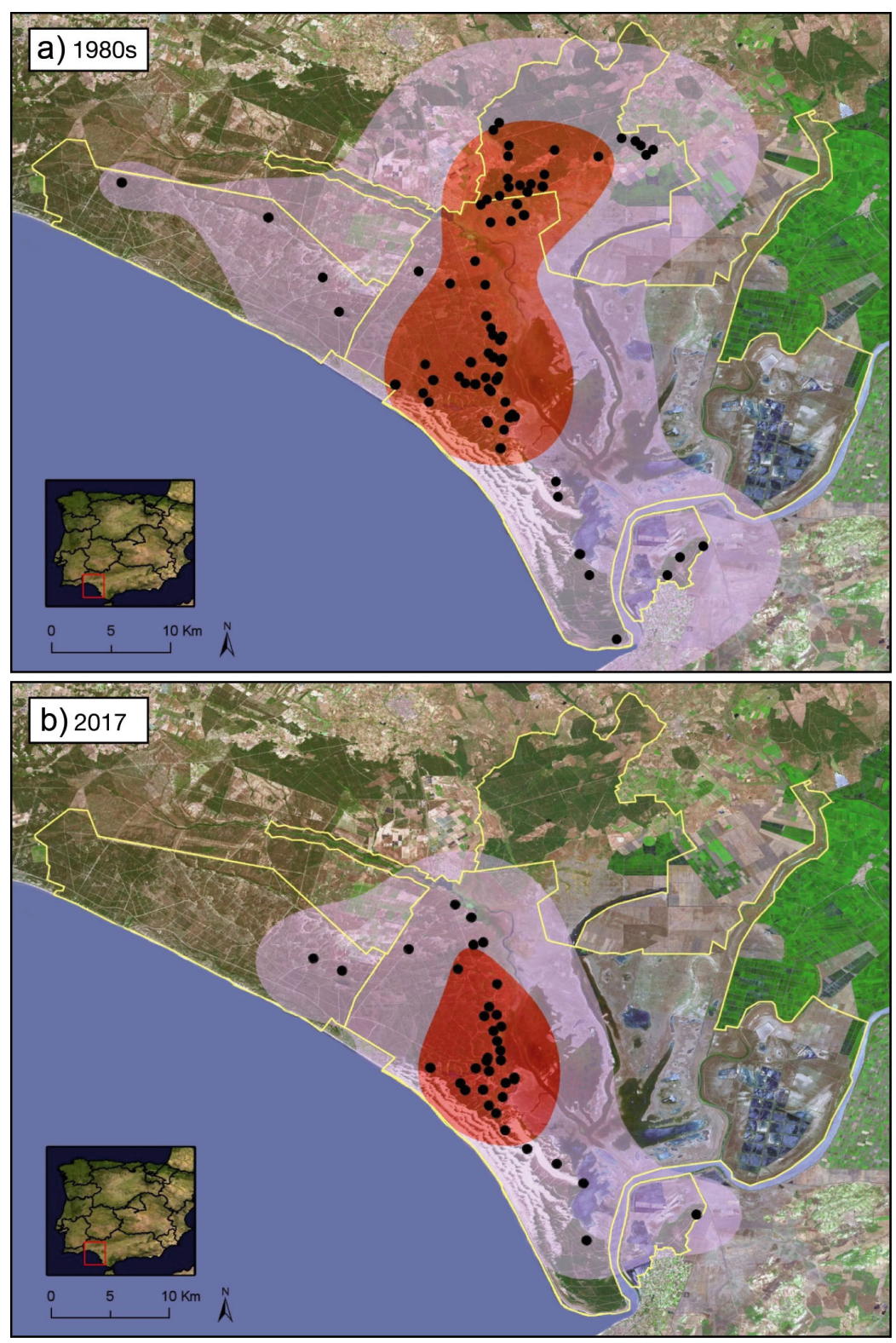

Fig. 4. Distribution range of red kites in Doñana (a) in the 1980 s and (b) in 2017. The pink, outer polygon represents a 95\% kernel constructed around the territory locations, while the red polygon is a $50 \%$ kernel showing the core area of distribution. The overall and core distribution range contracted by 53.4 and $58.1 \%$, respectively. Territory locations have been moved slightly for conservation reasons

Based on the model with minimum survival rates, which gave the best fit to past declines, the population of 37 pairs censused in 2017 would be reduced to 7 pairs within $10 \mathrm{yr}$ and virtually extinct ( $\leq 2$ pairs) in 17 yr. The less supported scenario of mean European survival estimates projected a population of 25 pairs in $10 \mathrm{yr}$, while the most optimistic scenario of maximum survival predicted a full recovery to the 1980 s population level of 70 pairs in $10 \mathrm{yr}$.
Despite the current extremely low breeding success, under all 3 scenarios of survival the population growth rate was least sensitive to changes in fledglings production $[E(F)=0.048-$ $0.079 ; S(F)=0.137-0.277]$ and most sensitive to variations in adult survival probability $[E(\theta)=0.843-0.904 ; S(\theta)=$ 0.929-0.955]. In Fig. 9, we plot the combination of fledgling production and adult survival that produce different levels of population growth. At current levels of reproduction, adult survival would have to be around $0.90-0.95$ to attain a stable or slightly increasing population, while restoring breeding success to the levels of the 1980 s of 1.3 young per pair would imply a stable population even with a relatively low adult survival of $\sim 0.77$, i.e. below the minimum ever recorded for the species (Fig. 9).

\section{DISCUSSION}

Our results showed that the current deteriorated condition of the Doñana red kite population was not a recent phenomenon, but the tip of the iceberg of decades of regional and local degradation. Although the protected area slowed the background levels of regional decline and likely saved the species from local extinction, its viability maintenance performance was far from satisfactory. In a way, the observed long-term deterioration acted as a protracted, diluted form of extinction debt (Tilman et al. 1994), paid over a time-frame of several decades. We suspect that similar conditions may be common in other protected areas, making this a classical example of gradual, underlying pressures, diluted over such a long time-frame that their severity becomes evident only through a large-scale, long-term assessment, or once population degradation has reached its extreme consequences. Note that, for many parameters, deterioration was not especially alarming from one decade to the next, making it difficult for the succession of local field observers to appreciate the overall severity of the long-term trends. This difficulty in 


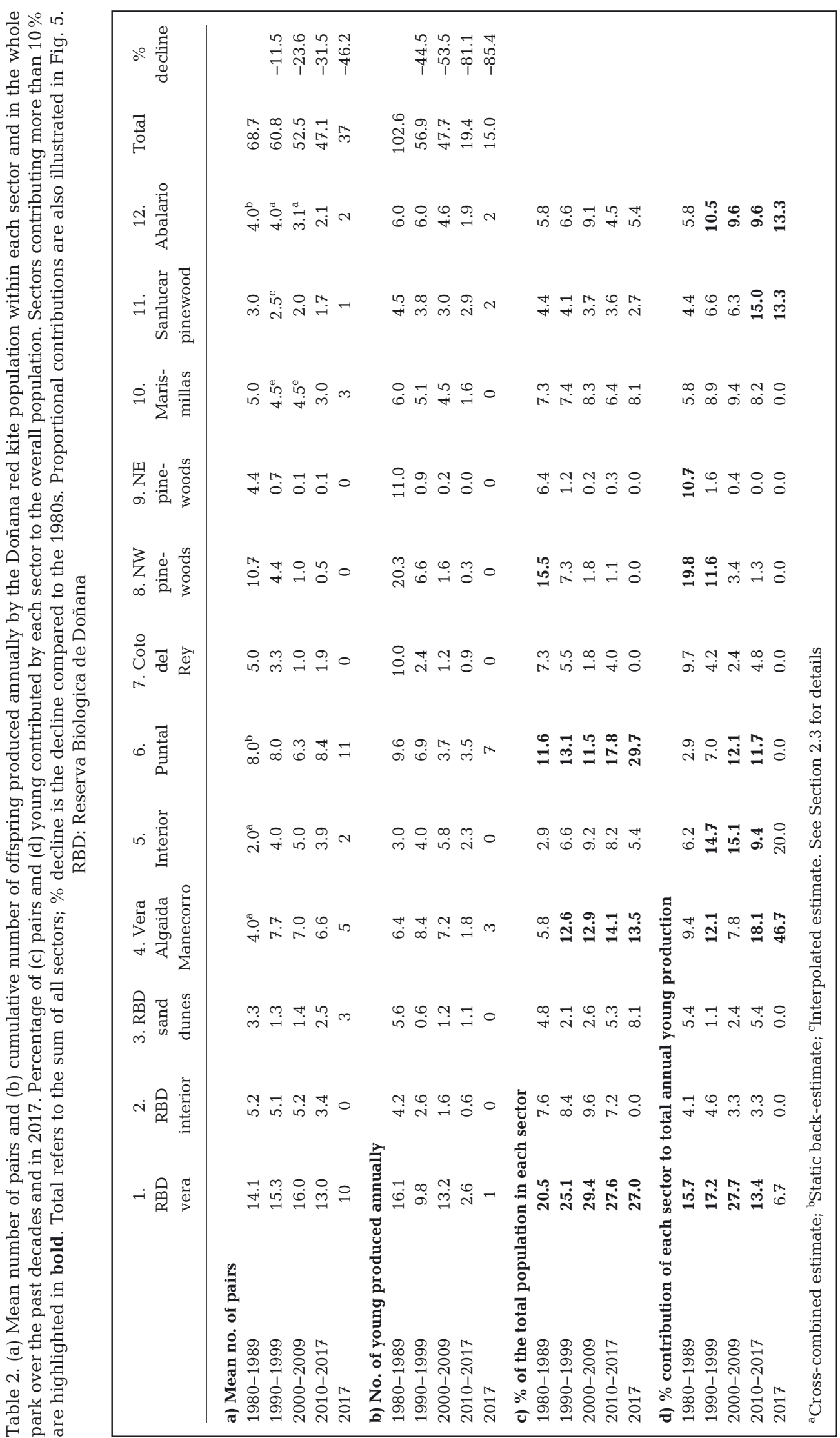



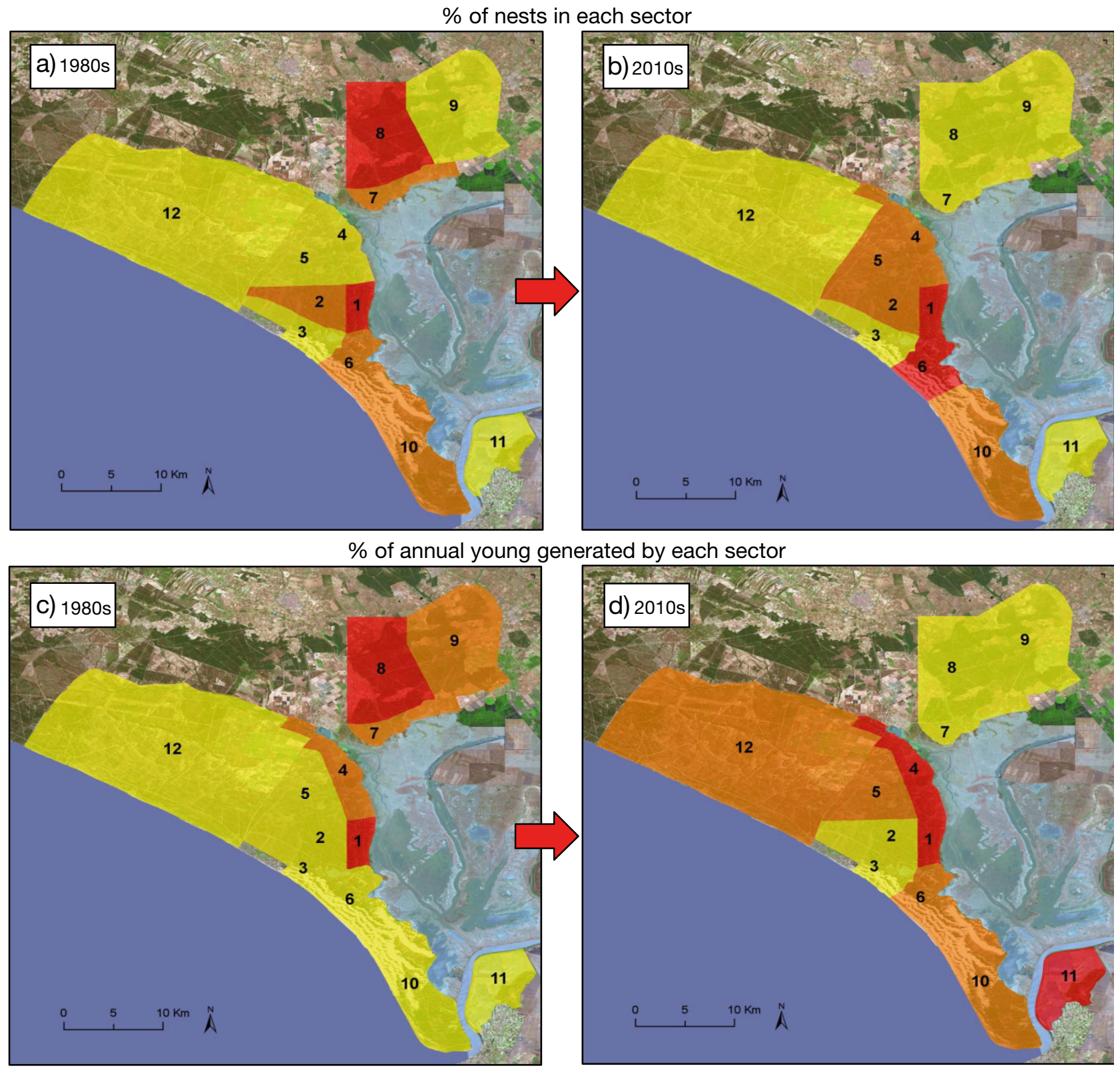

Fig. 5. Percentage of the total red kite population in each of 12 sectors of Doñana (a) in the 1980s and (b) in the 2010s; percentage of the annual young production generated by each sector (c) in the 1980s, and (d) in the 2010s. (a) In the 1980s, the bulk of the population was concentrated in northern sectors ( 7 and 8) and in the southern shores of the marshes (sectors 1,6 and 10). (b) In the $2010 \mathrm{~s}$, the population virtually disappeared from the northern sectors and became essentially confined to the national park, where it concentrated along the marshes. (c) In the 1980s, the population generated more than 100 young each year, most of them produced by the northern sectors $(7,8,9)$ and by the northern shores of the marshes (sectors 1 and 4$)$. (d) In the 2010s, the population generated less than 10 young, mostly generated close to wetlands (sectors 1, 4, 11), with homogeneously low numbers elsewhere. Colors (yellow $\rightarrow$ orange $\rightarrow$ red) classify sectors by tertiles of the range of percentage contribution

detecting the problem was likely exacerbated by the following factors that could be defined as 'perception obstacles': (1) The fact that a population becomes more and more restricted to a park is often used to illustrate the positive role of protected areas by focusing their performance assessments on range coverage, i.e. the capability of protected areas to cover a large portion of a species range (e.g. Czech 2005, Godet et al. 2007). This diverts attention from the wider problems of range contraction and from the actual performance of the park in terms of viability maintenance (Gaston et al. 2008). (2) Confinement to 

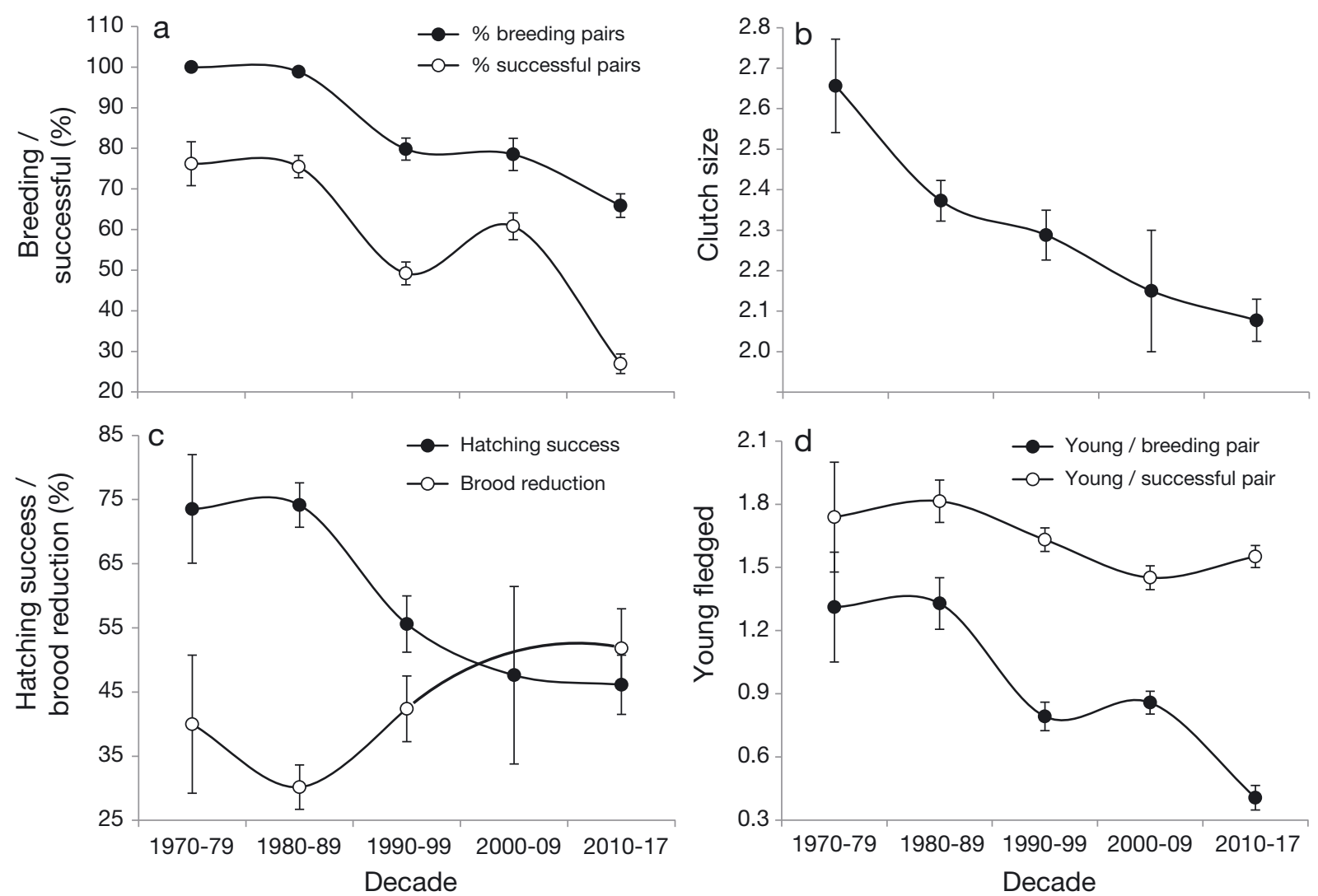

Fig. 6. Reproductive parameters of the red kite population of Doñana: (a) percentage of pairs laying eggs (black dots, $\mathrm{n}=804$ ) and successfully raising fledglings (white dots, $\mathrm{n}=1185$ ); (b) mean clutch size $(\mathrm{n}=469$ ); (c) hatching success (percentage of eggs that hatched, black dots, $\mathrm{n}=353$ ) and brood reduction (percentage of chicks that disappeared during the nestling period, white dots, $\mathrm{n}=240$ ); (d) mean number of young fledged per territorial pair (black dots, $\mathrm{n}=1145$ ) and per successful pair (white dots, $\mathrm{n}=576$ )

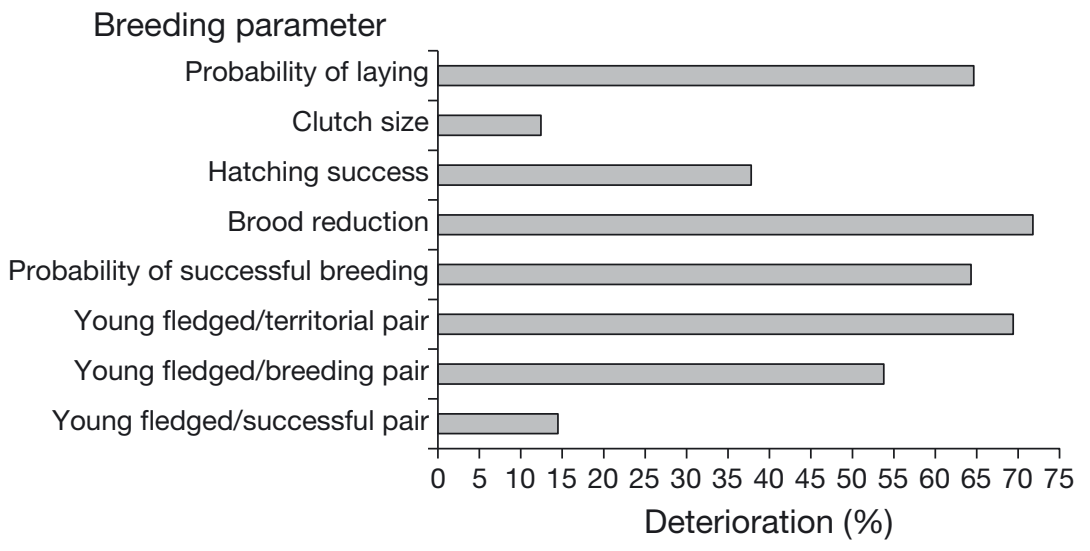

Fig. 7. Percentage deterioration of breeding parameters of the red kite population of Doñana between the 1980s and the 2010s

a protected area is usually accompanied by the automatic presumption that this will act as a source area with limited anthropogenic impacts, an assumption that is increasingly disproved (Hansen \& DeFries 2007, Gaston et al. 2008, Watson et al. 2014). (3) Longterm assessments such as ours required the lengthy collation of fragmented information from a large number of sequential field workers and administrations, each of which had a very limited perception of the overall situation. (4) Much monitoring was conducted in the core areas of the park, like the RBD, where the species has always been most abundant and relatively stable (e.g. Sergio et al. 2005), confusing the perception of broader declines. (5) Finally, large numbers of wintering migrants boost the population in the winter and early spring, often producing an optimistic impression of apparent abundance, even in relatively expert members of the public or of local administrations, as we frequently noted in public talks and private conversations.

Overall, the decline occurred at multiple levels: red kites were originally widespread throughout southern Spain (López 1861), but became progressively 


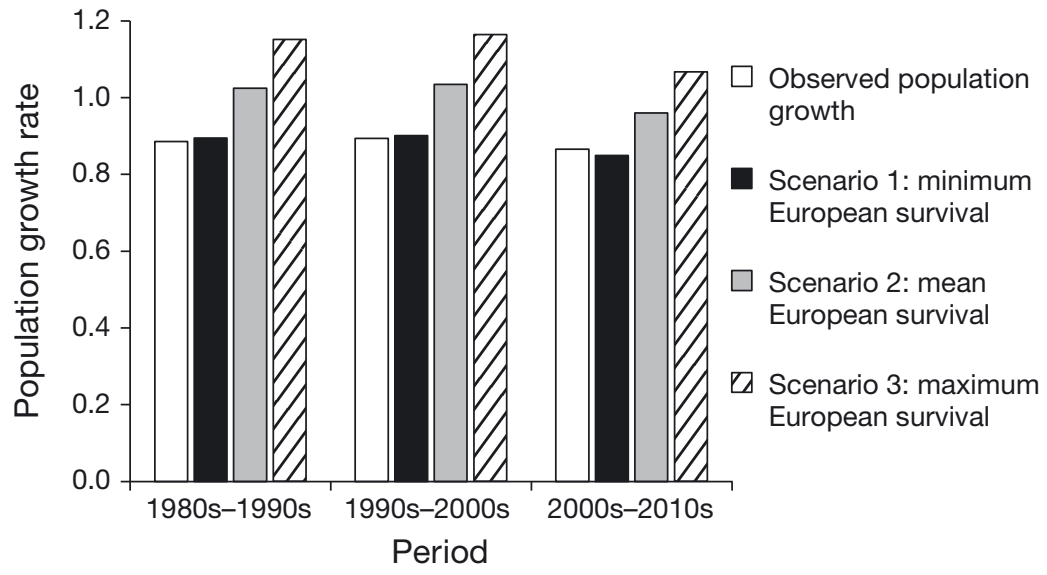

Fig. 8. Population growth of the Doñana red kite population during the past 4 decades, as predicted by matrix demographic models based on 3 scenarios which assumed that survival was equal to minimum, mean or maximum survival rates reported for other European populations (reviewed in Table 1). Predicted values are compared with observed declines from one decade to the next

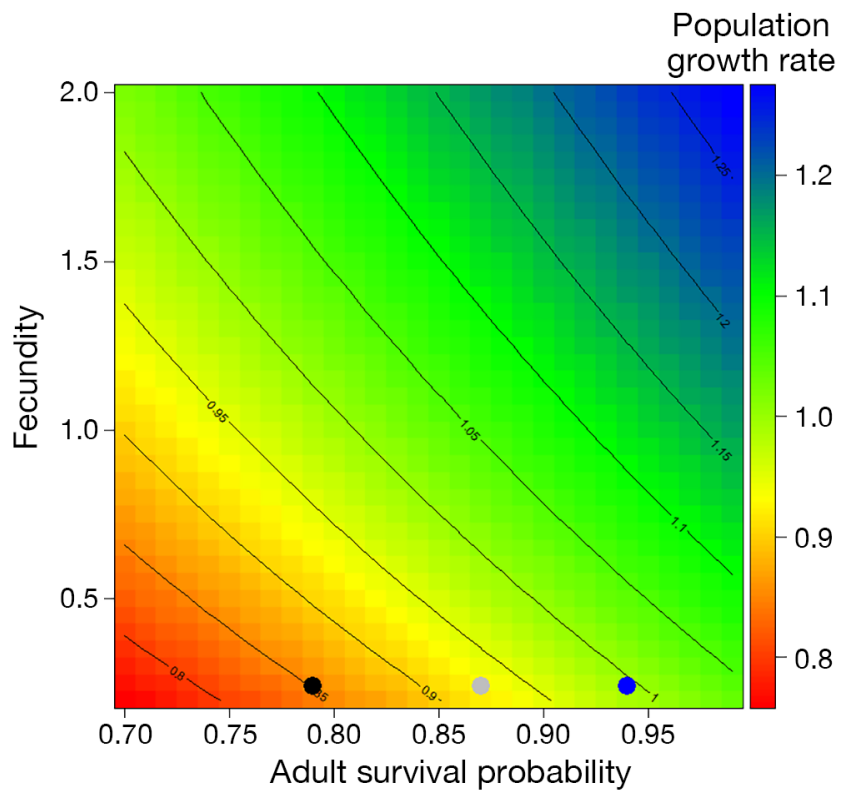

Fig. 9. Population growth rate of red kites in relation to adult survival and breeding performance (mean number of young fledged per territorial pair), based on a matrix population model. Note that the graph could be applied to any European population. The 3 points at the base of the graph represent the minimum (black), mean (grey) and maximum (blue) survival published for European populations (reviewed in Table 1)

confined to the protected area of Doñana in recent decades. However, the park did not confer automatic safety, and declines and range contraction also continued within the protected area, suggesting pervasive pressures and range erosion at multiple spatial scales. In particular, almost one third of the Doñana population was virtually eradicated from the northern pinewoods of the buffering Natural Park in 5 to $7 \mathrm{yr}$ between the late 1980s and early 1990s. Several lines of evidence suggest that illegal poisoning was the main cause of this eradication: (1) Several adults were found poisoned under their nest in those sectors and years. (2) Large-scale poisoning campaigns of raptors were reported throughout Spain in those exact same years, as a consequence of hunters' illegal attempts to control predator populations to increase the rapidly deteriorating numbers of small game (rabbits and partridges; Villafuerte et al. 1998, Viñuela \& Villafuerte 2003, Cano et al. 2008). In this sense, the National Park suffered much wider, national-level pressures. (3) The northern sectors of the park, where the eradication took place, included or were close to private small-game reserves, and predator control was well known to occur in some of them. (4) Finally, the rapidity of the eradication of such a longlived species (maximum longevity of $29 \mathrm{yr}$ in Doñana) implied a causative agent that directly affected adult mortality (Saether \& Bakke 2000), such as poisoning. The marked impact of poisoning on adult survival and population growth are well recognized for this species, whose facultative scavenging habits and foraging method of meticulous, low and slow quartering of the ground make it particularly sensitive to this threat (Smart et al. 2010, Tavecchia et al. 2012, Tenan et al. 2012, Sanz-Aguilar et al. 2015).

Spikes of rapid, local eradication were superimposed on more gradual but steady deterioration of offspring production. Gradual and continuous rather than sudden degradation of performance suggested that poisoning was not the only threat in effect. In this context, several factors may have contributed to gradually deteriorate ecological conditions for kites in recent decades: (1) Rabbit epidemics have caused progressive declines in the availability of this key prey (Viñuela \& Villafuerte 2003). (2) Lower prey availability may have exacerbated competition with the dense populations of other raptors with similar diets, such as the ecologically similar and increasing black kite. (3) Predation rates on adults and nestlings may have increased with the expansion of the populations of potential predators such as eagle owls Bubo bubo and goshawks Accipiter gentilis. (4) Recent assessments have detected alarming levels of toxic 
chemicals in red kite eggs from Doñana (Gómara et al. 2008). (5) Climate change and agricultural management have lowered the water table, with likely impacts on marsh inundation levels and aquatic prey (García Novo \& Marín Cabrera 2005, Díaz-Paniagua \& Aragonés 2015, Schmidt et al. 2017). (6) Conversion to intensive farmland in surrounding lands has eroded habitat and prey availability outside the protected area, which may have buffered kites from periods of low prey availability within the park (e.g. during droughts in the marshes). Some of the patterns of observed reproductive deterioration lend support to some of these impacts. For example, declining clutch sizes and increasing rates of brood reduction suggest that food was not sufficient to sustain earlier reproductive levels, while lowered hatching success is often the result of chemical contamination in raptors (review in Newton 1979). While each of these threats will be quantitatively investigated in detail in the immediate future, in the present context they illustrate the frequent and complex challenges faced by (1) protected areas in maintaining biodiversity and viable populations of imperiled species, and (2) conservation biologists in identifying causes of decline for subsequent management intervention, even in 'privileged' sites such as reserves.

Redistribution, declining numbers and performance had important repercussions for future viability: (1) The population passed from producing $>100$ annual young to $<10-20$, which will make maintenance and recovery difficult. (2) These young were increasingly produced in the core sectors of the marsh-ecotone within the National Park, which probably increased the dependence of the population on marsh inundation, in turn affected by problems operating outside the park (García Novo \& Marín Cabrera 2005, Díaz-Paniagua \& Aragonés 2015, Schmidt et al. 2017). (3) Steep declines in the percentage of successful pairs implied that future generations were produced by a progressively more restricted number of pairs, which will make the population more subject to inbreeding and stochastic events. For example, in the last 3 yr all the annual young were produced by 6,8 and 9 pairs, respectively suggesting an effective population size 4 to 9 times lower than the overall abundance.

Given all the above, it is no surprise that demographic models suggested a negative growth and a population incapable of self-sustenance. In particular, the model that gave the best fit to past observed declines was the one based on minimum European survival estimates, followed by the scenario based on mean European survival estimates. Given the above- mentioned threats, declines and performance deterioration, we would expect survival to be closer to minimum than mean European levels, as supported by the observed fit to past and recent declines. These results have 2 main implications: (1) If survival is as low as we suspect, demographic models predict virtual extinction within a few years, demanding an urgent need for identification and management of mortality threats, as well as quantification of actual survival to refine predictions. Note that virtual extinction could be even earlier when taking into account effective rather than total population size, and a stochastic rather than deterministic population model. (2) Should actual survival be confirmed low but further declines not observed, the population would be a sink sustained by external sources, which would make it even more at risk from anthropogenic threats outside the park and thus more challenging to manage (e.g. Hansen \& DeFries 2007, Blanco et al. 2017).

\section{Conclusions and implications for conservation}

The decades-long degradation that we depicted was likely generated by a combination of factors, both internal to the park (e.g. rabbit availability, marsh inundation rates, predation and competition with other species) and external (e.g. illegal poisoning, contamination, farmland intensification). Some of them will be amenable to management and others less so, but the first priority will be to find rapid ways to identify the key factors that drive population growth so as to optimize conservation action before it is too late. For example, focusing conservation 'blindly' on supplementary feeding could be useless if the problem is chemical contamination. The quickest way to obtain such information would be a satellite/GSM (Global System for Mobile communication) tagging program that would allow to: (1) obtain rapid estimates of health and survival for young and adults (e.g. Sergio et al. 2019), so as to recalibrate future projections and goals; (2) assess the relative contribution of main mortality causes, which is an essential first step in any recovery program (e.g. González et al. 2007, Margalida et al. 2008, Smart et al. 2010); and (3) identify the areas used by breeding and non-breeding individuals inside and outside of the park to assess their risk-exposure and intervene before or after death (e.g. to prosecute perpetrators of illegal poisoning, or retrofit dangerous electricity pylons in areas of high use by kites). 
Until this information becomes available, below we list some tentative figures and priorities for conservation. First of all, restoring the current population to former levels would undoubtedly be challenging and probably unrealistic given the profound changes incurred by the wider Doñana ecosystem in recent decades. Thus, we propose an initial target of 60 pairs as a long-term restoration goal. Elasticity analysis suggested that optimal management should focus on improving adult survival, which had the largest impact on population growth, as in other long-lived species (Saether \& Bakke 2000, Whitfield et al. 2004, Krüger et al. 2010). This could be attempted by increasing food availability, especially of key prey such as rabbits, and by curtailing mortality threats such as illegal poisoning, which still continues despite much effort to eradicate it by the local administration. The telemetry program outlined above could help to identify local perpetrators, as occurred in other populations (Smart et al. 2010, Tavecchia et al. 2012). On the other hand, despite their low elasticities, reproductive rates are currently so low that it would be fundamental to increase them, e.g. by increasing food availability and ensuring proper inundation of the marshes. Based on Fig. 5, we propose as initial targets for restoration: (1) survival rates equal or higher than the European mean (adult survival $\geq 0.87$ ); and (2) a number of young fledged per territorial pair above 1.0, which would produce an increasing population, provided that adult survival is equal to or above the European mean. Note that Fig. 5 could be applied to any European population as a tool to check its potential viability. Given the highly threatened status of red kites, the species' limited range confined to Europe and its ongoing declines, viability assessments such as ours may sadly become more important for the management and recovery of many populations.

In conclusion, red kites would probably be extinct in southern Spain without the institution of a large national park. In this sense, this example well illustrates how protected areas will continue to be cornerstones of global conservation of threatened taxa. However, their safety is not ensured by park institution per se, and performance monitoring and focused action will be needed to avoid potential extinction debts, which may be more protracted than previously appreciated. In our exemplary case, despite the presence of a large national park on prime fertile land within a developed country with adequate institutional and financial support, a key threatened species suffered latent but steady declines for decades, obscured by problems of perception, lack and frag- mentation of information, and likely caused by a complex array of within-park threats and growing external pressures. Viability maintenance and recovery will probably require concerted actions within and outside of the park, but only after detailed information on crucial aspects becomes available, which is probably the most urgent current priority. We suspect that dynamics like the ones illustrated here are more common than currently appreciated and will become more widespread as anthropogenic pressures increase around protected areas and as their performance monitoring becomes more prevalent.

Acknowledgements. We thank all the (too many to mention) researchers, field workers, visitors, volunteers, gamekeepers, park managers and wardens that have provided data since the 1960s. In particular, we thank F. G. Vilches, L. García and the Equipo de Seguimiento de Procesos Naturales of the Estación Biológica de Doñana-CSIC for help in the field. Special thanks to F. G. Vilches for the priceless help with the collation and organization of historical information. We thank J. P. Castellano, I. Redondo and all the 'Area de Conservación' of Doñana National Park for constant interest and support. We thank R. Cadenas, J. Madrid, R. Arenas, J. R. Benitez and all the pertinent personnel of the Consejería de Medio Ambiente of the Junta de Andalucía for information on current nest locations in the Sierra de Huelva and for their constant attentive support. We are grateful to Dr. N. Bunnefeld and 2 anonymous reviewers for constructive comments that improved the manuscript. This study was funded by the Foundation Jaime González-Gordon and by the research project $1602 / 2015$ of the Spanish Ministry of Agriculture, Food and the Environment (National Parks Autonomous Agency).

\section{LITERATURE CITED}

Beissinger SR, Ackerly DD, Doremus H, Machlis G (2017) Science, conservation and national parks. University of Chicago Press, Chicago, IL

* Blanco G, Cardells J, Garijo-Toledo MM (2017) Supplementary feeding and endoparasites in threatened avian scavengers: coprologic evidence from red kites in their wintering stronghold. Environ Res 155:22-30

*Bashares JS, Arcese P, Sam MK (2001) Human demography and reserve size predict wildlife extinction in West Africa. Proc Biol Sci 268:2473-2478

* Bustamante J (1993) Post-fledging dependence period and development of flight and hunting behaviour in the red kite Milvus milvus. Bird Study 40:181-188

Cano C, Ayerza P, Fernández J (2008) Poisoning in Spain (1990-2005): analysis of the problem, incidence and causes. WWF/Adena, Madrid (in Spanish)

Caswell H (2001) Matrix population models. Sinauer, Sunderland, MA

Ceballos JJ, Guimerá VM (1992) Guía de las aves de Jerez y de la Provincia de Cádiz: atlas ornitológico de las especies nidificantes. Ayuntamiento de Jerez, Jerez

Craigie ID, Baillie JEM, Balmford A, Carbone C, Collen B, Green RE, Hutton JM (2010) Large mammal population 
declines in Africa's protected areas. Biol Conserv 143: 2221-2228

* Czech B (2005) The capacity of the National Wildlife Refuge System to conserve threatened and endangered animal species in the United States. Conserv Biol 19: $1246-1253$

Delibes M, García L (1984) Hábitos alimenticios del milano real en Doñana durante el periodo de cría. Ardeola 31: 115-121

Díaz-Paniagua C, Aragonés D (2015) Permanent and temporary ponds in Doñana National Park (SW Spain) are threatened by desiccation. Limnetica 34:407-424

Evans IM, Summers RW, O'Toole L, Orr-Ewing DC, Snell N, Smith J (1999) Evaluating the success of translocating red kites Milvus milvus to the UK. Bird Study 46:129-144

Ferrer M, Hiraldo F (1991) Evaluation of management techniques for the Spanish imperial eagle. Wildl Soc Bull 19: 436-442

García Novo F, Marín Cabrera C (2005) Doñana: water and biosphere. Doñana 2005 Project. Spanish Ministry of the Environment, Madrid

* Gaston KJ, Jackson SF, Cantú-Salazar L, Cruz-Piñón G (2008) The ecological performance of protected areas. Annu Rev Ecol Evol Syst 39:93-113

Godet L, Devictor V, Jiguet F (2007) Estimating relative population size included within protected areas. Biodivers Conserv 16:2587-2598

* Gómara B, González MJ, Baos R, Hiraldo F, Abad E, Rivera J, Jiménez B (2008) Unexpected high PCB and total DDT levels in the breeding population of red kite (Milvus milvus) from Doñana National Park, south-western Spain. Environ Int 34:73-78

*González LM, Margalida A, Mañosa S, Sánchez R and others (2007) Causes and spatio-temporal variations of nonnatural mortality in the vulnerable Spanish imperial eagle Aquila adalberti during a recovery period. Oryx 41:495-502

Hansen AJ, DeFries R (2007) Ecological mechanisms linking protected areas to surrounding lands. Ecol Appl 17: 974-988

Hernández FJ, Donázar JA, Hiraldo F (2001) Evaluación del uso de venenos para el control de predadores en la Comunidad Autónoma Andaluza y su impacto en la conservación de especies amenazadas de vertebrados. Consejeria de Medio Ambiente and Estación Biológica de Doñana, Sevilla

IUCN (The World Conservation Union) (1994) Guidelines for protected area management categories. IUCN, Gland

Knott J, Newbery P, Barov B (2009) Action plan for the red kite Milvus milvus in the European Union. European Commission, Brussels

Krüger O, Grünkorn T, Struwe-Juhl B (2010) The return of the white-tailed eagle (Haliaeetus albicilla) to northern Germany: modelling the past to predict the future. Biol Conserv 143:710-721

López V (1861) Catálogo de las aves observadas en Andalucía. Madrid

López G and others (2009) Management measures to control a feline leukemia virus outbreak in the endangered Iberian lynx. Anim Conserv 12:173-182

Margalida A, Heredia R, Razin M, Hernández M (2008) Sources of variation in mortality of the bearded vulture Gypaetus barbatus in Europe. Bird Conserv Int 18:1-10

Naughton-Treves L, Holland MB, Brandon K (2005) The role of protected areas in conserving biodiversity and sustain- ing local livelihoods. Annu Rev Environ Resour 30: 219-252

Newton I (1979) Population ecology of raptors. T \& AD Poyser, Berkhamsted

Newton I, Davis PE, Davis JE (1989) Age of first breeding, dispersal and survival of red kites Milvus milvus in Wales. Ibis 131:16-21

Otero C, Castién E, Senosiaín R, Portillo F (1978) Fauna de Cazorla: vertebrados. Publicaciones del Ministerio de Agricultura, Madrid

Parks SA, Harcourt AH (2002) Reserve size, local human density, and mammalian extinctions in U.S. protected areas. Conserv Biol 16:800-808

R Development Core Team (2018) R: a language and environment for statistical computing. R Foundation for Statistical Computing, Vienna. www.r-project.org

* Sæther BE, Bakke Ø (2000) Avian life history variation and contribution of demographic traits to the population growth rate. Ecology 81:642-653

* Sanz-Aguilar A, De Pablo F, Donázar JA (2015) Age-dependent survival of island vs. mainland populations of two avian scavengers: delving into migration costs. Oecologia 179:405-414

Schaub M (2012) Spatial distribution of wind turbines is crucial for the survival of red kite populations. Biol Conserv 155:111-118

Schmidt G, Sánchez Navarro R, Hernández E, Carmona, JJ, Fuentelsaz F, Seiz R (2017) The state of water in Doñana: an evaluation of the state of the water and of the ecosystems of the protected space. WWF/Adena, Madrid

F Scott JM, Davis FW, McGhie RG, Wright RG, Groves C, Estes J (2001) Nature reserves: Do they capture the full range of America's biological diversity? Ecol Appl 11: 999-1007

* Seoane J, Viñuela J, Díaz-Delgado R, Bustamante J (2003) The effects of land use and climate on red kite distribution in the Iberian peninsula. Biol Conserv 111:401-414

Sergio F, Blas J, Feroro $M$, Fernández N, Donázar JA, Hiraldo F (2005) Preservation of wide-ranging top predators by site-protection: black and red kites in Doñana National Park. Biol Conserv 125:11-21

* Sergio F, Tanferna A, Blas J, Blanco G, Hiraldo F (2019) Reliable methods for identifying animal deaths in GPS- and satellite-tracking data: review, testing and calibration. J Appl Ecol 56:562-572

* Smart J, Amar A, Sim IMW, Etheridge B, Cameron D, Christie G, Wilson JD (2010) Illegal killing slows population recovery of a re-introduced raptor of high conservation concern - the red kite Milvus milvus. Biol Conserv 143:1278-1286

Tavecchia G, Adrover J, Muñoz Navarro A, Pradel R (2012) Modelling mortality causes in longitudinal data in the presence of tag loss: application to raptor poisoning and electrocution. J Appl Ecol 49:297-305

* Tenan S, Adrover J, Muñoz Navarro A, Sergio F, Tavecchia G (2012) Demographic consequences of poison-related mortality in a threatened bird of prey. PLOS ONE 7: e49187

* Tilman D, May RM, Lehman CL, Nowak MA (1994) Habitat destruction and the extinction debt. Nature 371:65-66

Torres Esquivias JA, Jordano P, León A (1981) Aves de presa diurnas de la provincia de Córdoba. Publicaciones C.A. y M.P., Córdoba

*Veiga JP, Hiraldo F (1990) Food habits and the survival and growth of nestlings in two sympatric kites (Milvus milvus 
and Milvus migrans). Holarct Ecol 13:62-71

Villafuerte R, Viñuela J, Blanco JC (1998) Extensive predator persecution caused by population crash in a game species: the case of red kites and rabbits in Spain. Biol Conserv 84:181-188

Viñuela J (2004) Milano real, Milvus milvus. In: Madroño A, González C, Atienza JC (eds) Libro rojo de las aves de España. Dirección General para la Biodiversidad-SEO/ BirdLife, Madrid, p 120-125

Viñuela J, Villafuerte R (2003) Predators and rabbits (Oryctolagus cuniculus) in Spain: a key conflict for European raptor conservation. In: Thompson DBA, Redpath SM, Fielding AH, Marquiss M, Galbraith CA (eds) Birds of prey in a changing environment. The Stationery Office, Edinburgh, p 511-526

Editorial responsibility: Nils Bunnefeld, Stirling, UK
Viñuela J, Martí R, Ruiz A (eds) (1999) El milano real en España. SEO/Birdlife, Madrid

*Watson JEM, Dudley N, Segan DB, Hockings M (2014) The performance and potential of protected areas. Nature 515:67-73

Whitfield SM, Bell KE, Philippi T, Sasa M and others (2007) Amphibian and reptile declines over 35 years at La Selva, Costa Rica. Proc Natl Acad Sci USA 104:8352-8356

*Whitfield DP, Fielding AH, McLeod DRA, Haworth PF (2004) Modelling the effects of persecution on the population dynamics of golden eagles in Scotland. Biol Conserv 119:319-333

Zuur A, Ieno EN, Walker N, Saveliev AA, Smith GM (2009) Mixed effects models and extensions in ecology with R. Springer, New York, NY

Submitted: October 8, 2018; Accepted: January 28, 2019 Proofs received from author(s): April 7, 2019 